\title{
Erratum to: Characteristics of People Who Use Telephone Counseling: Findings from Secondary Analysis of a Population-Based Study
}

Bridget Bassilios • Meredith Harris •

Aves Middleton · Jane Gunn · Jane Pirkis

Published online: 18 November 2014

(C) Springer Science+Business Media New York 2014

Erratum to: Adm Policy Ment Health

DOI 10.1007/s10488-014-0595-8

Unfortunately, the $p$-value of ".909" in Table 2 was set in bold in the original publication. The author would like to correct the error with this erratum.

The $p$-value of .909 associated with employment status in Table 2 should not be in bold.

The online version of the original article can be found under doi:10.1007/s10488-014-0595-8.

B. Bassilios $(\bowtie) \cdot J$. Pirkis

Centre for Mental Health, Melbourne School of Population and

Global Health, The University of Melbourne, Victoria 3010,

Australia

e-mail: b.bassilios@unimelb.edu.au

M. Harris

School of Population Health, The University of Queensland,

Brisbane, Australia

A. Middleton · J. Gunn

General Practice and Primary Health Care Academic Centre,

The University of Melbourne, Melbourne, Australia 